\title{
Effect of duration of contraceptive use on coagulation screening tests in healthy Nigerian women on hormornal contraceptive
}

${ }^{\cdot 1}$ Abubakar SB, ${ }^{2}$ Mamman AI, ${ }^{3}$ Abdul MA, ${ }^{4}$ Yunusa A 1. Dept of Haematology and Blood Transfusion, Usmanu Danfodiyo University Teaching Hospital, Sokoto. 2. Dept of Haematology and Blood Transfusion, Ahmadu Bello University \& Teaching Hospital, Zaria. 3. Dept of Obstetrics and Gynaecology, Ahmadu Bello University \& Teaching Hospital, Zaria. 4. Dept of Pharmacology and Therapeutics, Faculty of Basic Medical Sciences, College of Health Sciences, Usmanu Danfodiyo University Sokoto, Nigeria.

4. Dept of Pharmacology and The
Hospital, Sokoto. Email-
sbabubakar@yahoo.com

\section{ABSTRACT}

Background: Hormonal contraceptives have been associated with alteration in haemostatic profile resulting in increased risk of thromboembolic disorders.

Objective: The objective of the study was to determine the effect of duration of hormonal contraceptives use on haemostatic parameters.

Subjects and Methods: This is a cross sectional study involving 140 consenting subjects who were on hormonal contraceptives for different period ranging from 6 to 42 months. A structured questionnaire was administered to obtain information required. Venous blood samples were collected into appropriate containers for FBC and assay of haemostatic parameters (PT, APTT and TT) using standard methods. The results were analyzed using the statistical package for social sciences (SPSS) version 17.0 software. Statistical significance was based on $p$ value $<0.05$.

Results: The subjects were classified based on the duration of contraceptive used into six monthly intervals and the mean tests result for each group obtained. There was progressive shortening of the PT and APTT from $12.30 \pm 1.33$ and $29.97 \pm 5.03$ seconds at $7-12$ months to $10.93 \pm 1.31$ and $26.60 \pm 5.02$ at $37-42$ months respectively. The TT also shortened from $18.26 \pm 2.59$ at $7-12$ months and $16.05 \pm 1.64$ at $37-42$ months. The platelets count shows a gradual raise from $252.94 \pm 10.36$ at $7-12$ to $316.17 \pm 31.94$ at 37 42 months.

Conclusion: The use of hormonal contraceptives affects the haemostatic parameters resulting in increase thrombogenic risk which worsens with duration of use. We therefore recommend that before commencement of hormonal contraceptives, women should have a base line coagulation screening test and if feasible, monitored at six monthly intervals.

\section{INTRODUCTION}

The term contraception includes all measures temporary or permanent designed to prevent pregnancy due to coital act. ${ }^{1}$ Hormonal contraception refers to birth control methods that act on the endocrine system. They are usually formulated as a combination of oestrogens and progestogens or progestogens only. ${ }^{2}$ They act on the hypothalamus and pituitary decreasing the pulsatile release of gonadotrophin releasing hormone and follicle stimulating hormone from the hypothalamus and pituitary respectively. This suppresses ovarian activity with resultant failure of follicular maturation and absence of ovulation. They also induce endometrial changes that make it unreceptive to the blastocyst. In addition, the progestogens alter tubal epithelium and cause increase in the viscosity of cervical mucous thus adversely affecting the gamete motility and transport. ${ }^{2}$

The history of development of modern hormonal contraceptives have mostly been attributed to the work of Ludwig Haberlandt in 1921 when he demonstrated a temporary hormonal contraception in female rabbit by 
transplanting ovaries from a second pregnant animal. ${ }^{3}$ However it was much later, in 1960 that the first hormonal contraceptive; the combined oral contraceptive pill (COCP) enovid $^{\circledR}$ was approved for human use. ${ }^{4}$ Subsequently there was development of others form of hormonal contraceptives which include progesterone-only contraceptive pills, progesterone only injectable contraceptives and methods providing constant release such as sub dermal implants and vaginal rings which contain estradiol or low dose progestogens.

The number of women of child bearing age using hormonal contraceptives is on the increase worldwide. ${ }^{5}$ In Nigeria the prevalence of hormonal contraceptive use rose from $3 \%$ in 1990 to $10 \%$ in $2008 .{ }^{6}$

Hormonal contraceptive has been shown to cause increased levels of prothrombin, factor VII, factor VIII, factor $\mathrm{X}$ and fibrinogen. ${ }^{7}$ These changes result in augmented procoagulant activity with a resultant increase tendency for thrombus formation. Added risk factors for thromboembolism are stasis, increased platelet activation, inhibition of fibrinolysis and decreased naturally occurring anticoagulant activity. ${ }^{8,9}$ Elevated levels of thrombin-activatable fibrinolysis inhibitor (TAFI) has also been demonstrated among hormonal contraceptive users which is an additional risk factor for venous thrombosis. ${ }^{10}$

Numerous studies have shown significant haemostatic derangement among hormonal contraceptive users. However, there is need for more understanding of the effect of the duration of use and even the hormonal content of the contraceptive on these changes to guide the care providers as well as the clients.

\section{SUBJECTS AND METHODS}

This was a cross sectional study carried out on clients attending the reproductive health clinic, Department of Obstetrics and Gynecology and the samples were analyzed at the Department of Haematology Ahmadu Bello University Teaching Hospital (ABUTH) Zaria.
Zaria is a metropolitan city that is known as an international centre for both Western and Islamic education. Hausa and Fulani are the indigenous tribes, however almost all ethnic groups and tribes in Nigeria are also found. The city is located in Kaduna State northwestern Nigeria and serves as a link to all major cities in the sub region by road, rail and occasionally by air.

The ABUTH Reproductive health clinic has an average of 355 clients monthly. About 1,380 clients are on hormonal contraceptives. The clientele were mostly resident in Zaria and others from neighbouring towns of Kaduna, Makarfi, Funtua, Hunkuyi and Gusau.

Ethical clearance was obtained from the hospital Health Research Ethics Committee. Consecutive subjects who were on hormonal contraceptives for at least six months with absence of intercurrent medical illness and no previous history suggestive of haemostatic disorders were enrolled into the study as they presented to the clinic for routine follow up (convenient sampling method) after obtaining there informed and written consent.

A total of 140 subjects on different forms of hormonal contraceptives (Oral, injectables, intradermal implant, and hormone containing IUD) were recruited into the study. A structured questionnaire was administered to obtain relevant demographic data and other information required. Two and half $(2.5 \mathrm{mls})$ of venous blood was collected into EDTA bottle for Complete Blood Count using the Sysmex ST 2000i Haematology Analyzer. Also $4.5 \mathrm{mls}$ was collected into a test bottle containing $0.5 \mathrm{mls}$ of $3.2 \%$ Sodium citrate for assay of haemostatic parameters namely; Prothrombin time (PT), Activated partial thromboplastin time (APTT) and Thrombin time (TT) using the STAGO STart ${ }^{\circledR} 4$ coagulation analyzer. All tests were done using standard methods according to manufacturer's instructions. The results were analyzed using the statistical package for social sciences (SPSS) version 
17.0 software. Statistical significance was based on $p$ value $<0.05$. Clients with abnormal results were contacted, informed and referred to appropriate clinics.

\section{RESULTS}

The Majority (95.7\%) of the participants were married. Hausa/Fulani were the predominant ethnic group which accounted for $50.0 \%$ and $67.1 \%$ were Muslims. Over $86.0 \%$ of the participants have some level of formal education and $63.6 \%$ were gainfully employed.

The subjects were on various forms of hormonal contraceptives, COCP being the most commonly used $(36.4 \%)$, Noristerat ${ }^{\circledR}$ (23.6\%), Implanon $\AA(19.3 \%)$, Depo Provera ${ }^{\circledR}$ (12.9\%), hormonal IUCD (5.7\%) and POP (2.1\%) Figure 1.

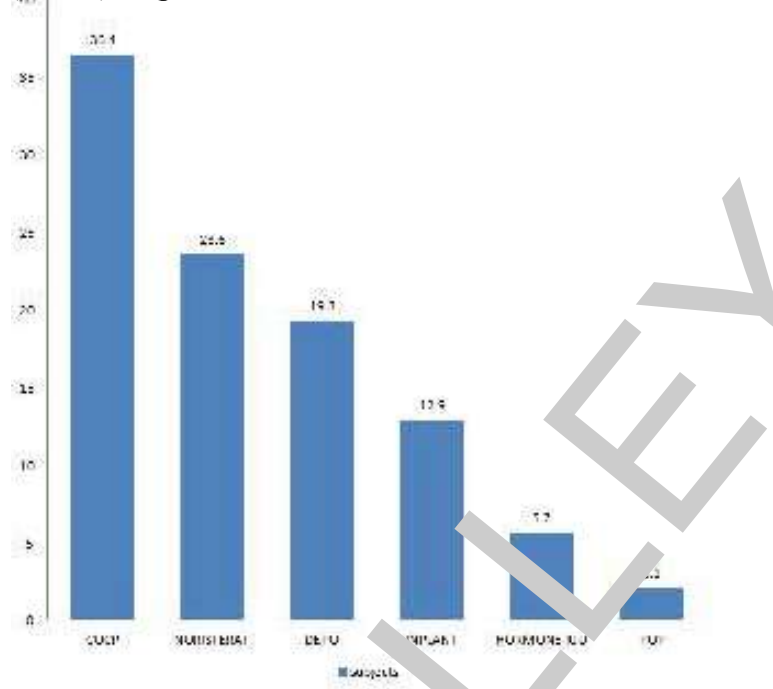

Figure 1: type of contraceptives used by participants

The mean PT at 7-12 months of use was $12.30 \pm 1.33$ and shows a gradual shortening to $10.93 \pm 1.31$ in those that have used the contraceptive for 37-42 months. A similar trend was also seen in the APTT results which show a shortening from $29.97 \pm 5.03$ at $7-12$ months to $26.60 \pm 5.02$. The TT remained within normal limit in all the groups a shortening was also noted from $18.26 \pm 2.59$ to $16.05 \pm 1.64$ at $7-12$ and $37-42$ months respectively.

Table 1: Duration of contraceptive use and

\section{haemostatic parameter $\mathrm{s}$}

\begin{tabular}{cccccc}
\hline $\begin{array}{l}\text { Duration of } \\
\text { contraceptive } \\
\text { use (months) }\end{array}$ & $\begin{array}{l}\text { Frequency } \\
(\mathrm{n}=140)\end{array}$ & $\begin{array}{l}\text { Mean PT } \\
(\text { seconds) }\end{array}$ & $\begin{array}{l}\text { MeanAPTT } \\
\text { (seconds) }\end{array}$ & $\begin{array}{l}\text { MeanTT } \\
\text { (seconds) }\end{array}$ & $\begin{array}{l}\text { Platelets count } \\
\mathbf{X} 109 /\end{array}$ \\
\hline $7-12$ & 35 & $12.30 \pm 1.33$ & $29.97 \pm 5.03$ & $18.26 \pm 2.59$ & $252.94 \pm 10.36$ \\
$13-18$ & 25 & $11.26 \pm 1.05$ & $27.60 \pm 4.09$ & $17.56 \pm 1.51$ & $252.36 \pm 13.16$ \\
$19-24$ & 30 & $11.26 \pm 1.10$ & $27.37 \pm 2.79$ & $16.76 \pm 1.56$ & $277.53 \pm 12.72$ \\
$25-30$ & 10 & $11.75 \pm 1.53$ & $29.96 \pm 4.59$ & $18.36 \pm 3.28$ & $278.20 \pm 15.81$ \\
$30-36$ & 13 & $10.82 \pm 0.95$ & $26.42 \pm 3.57$ & $16.96 \pm 1.25$ & $276.92 \pm 21.06$ \\
$37-42$ & 6 & $10.93 \pm 1.31$ & $26.60 \pm 5.02$ & $16.05 \pm 1.64$ & $316.17 \pm 31.94$ \\
\hline
\end{tabular}

Reference values: Platelet count (132-4, 77 $\mathrm{x} 10^{9)},{ }^{11}$ PT $12-17$ seconds, APTT 30 40seconds, TT 15-25seconds, Fibrinogen 180$400 \mathrm{mg} / \mathrm{dl}$, D-dimer $<400 \mathrm{ng} / \mathrm{ml}$, proteins C $65-130 \%$ activity.

\section{DISCUSSION}

The majority of the participants in this study $(81.0 \%)$ had at least secondary school education. Also, over two thirds of the participants (69.0\%) are either civil servants or are engaged in some form of trading. These findings are in agreement with the NDHS 2008 report that women with post secondary education and those with higher socioeconomic status use modern contraceptives more than their socially and economically disadvantaged counterparts ${ }^{6}$. Similar findings were reported in separate studies carried out by Sambo et $a l^{2}$ and the International Union for the Scientific Study of Population (IUSSP) in Zaria. ${ }^{13}$

Combined oral contraceptive was the most common hormonal form used by participants in this study (39.4\%). This is in conformity with the NDHS 2008 report $^{4}$ and data from many parts of the world. ${ }^{14}$ In fact COCP has been described as the most widely used contraceptive in the world, with over 100 million users. ${ }^{14}$

Obvious abnormalities in some of the 
haemostatic parameters manifested as shortening of the times below normal levels were noticed after six months of hormonal contraceptive use (minimal duration for inclusion in the study). These derangements, which tilt the user to a hypercoagulable state, persist throughout the duration of use included in this study (i.e 42 months). However an important observation noticed in this study is that around the 25 - 30 months of use there is an upsurge in the all the parameters measured, to almost normal levels. Thereafter a more severe derangement occurred. Similar trend was noticed in the platelets count. This observed pattern could be as a result of physiological adaptation of the body system to the drugs and an attempt to correct and maintain natural haemostatic balance. With failure of the physiological mechanism to correct the mechanism, the hypecoagulable state not only persist but worsen resulting in increase risk of developing venous thromboembolic disorders. Selection criteria have limited the observation of these parameters in earlier than the sixth month as significant haemostatic changes occurring as early as the first, ${ }^{15}$ third $^{16}$ and fourth month ${ }^{17}$ have been reported in other studies which were longitudinal. However a minimum of six month was used as cut off for inclusion in this study to allow time for elimination of any confounding factor such as recent childbirth, or change in type of hormonal contraceptive used because it was a cross sectional study.

Effect of duration of contraceptive use on haemostatic changes was also reported by Famodu, ${ }^{18}$ who carried out serial monitoring of serum fibrinogen concentration in COCP users over three years period at six month intervals and found a consistently significant rise throughout the period. A corresponding prolongation of euglobulin clot lysis time which is an indicator of decreased fibrinolytic activity was also observed. ${ }^{18}$ Other longitudinal studies such as that of Ajayi et al ${ }^{7}$ and Vessey et al ${ }^{19}$ also reported serial increase in haemostatic derangement with duration of use.

\section{CONCLUSION}

The use of hormonal contraceptives causes an alteration in haemostatic parameters resulting in a hypercoagulable state which worsens with duration of use therefore, conferring a higher risk of thromboembolic disorder on the user. Though none of the participants has any clinically overt thromboembolic condition, the alteration in haemostatic parameters recorded showed that Nigerian women on hormonal contraceptives like their counterparts elsewhere may have an increased thrombogenic risk.

We therefore recommend that women intending hormonal contraceptives should have a base line coagulation screening test before commencement and if feasible, at six monthly intervals.

\section{REFERENCES}

1. Hiralal Kona (ed). Contraceptives; in DC Dutta's textbook of gynaecology Jaypee Brothers Medical publishers (P) LTD New Delhi: $6^{\text {th }}$ ed 2013; 475.

2. McNaughton MC. Hormonal contraceptive: development and mode of action. In Loudon N (Ed). Handbook of Family Planning. Churchill Livingstone, New York. 1986; 40-49.

3. Müller-Jahncke WD. Ludwig Haberlandt (1885-1932) and the Development of Hormonal Contraception. Z Gesamte Inn Med.1988;43(15): 420 - 422.

4. Junod SW, Marks L. Women's trials: the Approval of the First Oral Contraceptive 
Pill in the United States and Great Britain. J Hist Med Allied Sci. 2002; 57 (2): 117160.

5. WHO Statistical Information System. Available at www.who .int/whosis /data/ Search.jsp. [Accessed $2^{\text {nd }}$ January 2011].

6. Family planning: National Population Commission (NPC) and ICF Macro. 2009. Nigeria Demographic and Health Survey. 2008: Key Findings. Calverton, Maryland, USA: NPC and ICF Macro. 5-6

7. Middeldorp S, Meijers JCM, van den Ende AE, . Effects on Coagulation of Levonorgestrel- and Desogestrelcontaining Low Dose Oral Contraceptives: a cross-over study. ThrombHaemost. 2000; 84:4-8.

8. George PC. Hormonal contraception. In Betram GK (ed). Basic and clinical pharmacology. McGraw-Hills Companies New York. $9^{\text {th }}$ ed 2006; 673-678.

9. Vandenbroucke JP, Koster T, BrietE,Reitsma PH, Bertina RM, Rosendel FR. Increased risk of venous thrombosis in oral-contraceptive users who are carriers of factor V Leiden mutation. Lancet. 1994; 344: 1453-1457.

10. van Tilburg NH, Rosendaal FR, Bertina RM. Thrombin Activatable Fibrinolysis Inhibitor and the risk for Deep Vein Thrombosis. Blood. 2000; 95: 2855- 2859.

11. Isa AH, Hassan A, Garba Y, Ijei IP. Reference ranges of some haematological parameters in healthy northern Nigerian adults. Jos Journal of Med. 2012; 6(3): 1618.

12. Aliyu AA, Shehu AU, Sambo MN, Sabitu K. Contraceptive knowledge, attitudes and practice among married women in Samaru community, Zaria, Nigeria.East Afr J

Public Health. Dec 2010 ; 7(4): 342-344.

13. International union for the scientific study of population (IUSSP). Knowledge and use of modern contraceptives among Muslim women in Zaria, Nigeria. Available at iussp 2005. princeton.edu/ papers/50788. [Accessed $27^{\text {th }}$ January 2013].

14. Cardiovascular Disease and Steroid Hormone Contraception: Report of a WHO Scientific group. WHO Tech Rep Ser 1998; 877: 1-89.

15. Ajayi O, Ajayi O. Obarhua E. Haemostatic Evidence of Thrombotic Signaling in Nigerian Women on Injectable Contraceptives. Haematologica. 2007; 92[suppl.2]:434.

16. Babatunde AS, Olatunji PO. Short term effect of oral contraceptive pills on some haemostatic parameters in healthy Nigerian women. The Nigerian Postgraduate Medical Journal.2004; 11 (4): $246-250$.

17. Ahmed JA, and Muna AK. Effect of combined oral contraceptive pills on some haemostatic parameters. Ann. Coll. Med. 2007; 33 (1\&2): 66-69.

18. Famodu AA. Serial changes in plasma fibrinogen concentration and fibrinolytic activity in African women on oral contraceptive pills. Afr J Reprod Health. 1997; 1:90-95.

19. Vessey MP, Doll R, Peto R, Johnson B, Wiggins P. A Long-term Follow-up Study of Women using Different Methods of Contraception-an interim Report. J Biosoc Sci. 1976; 8:373-427. 